\title{
Síndrome de Turner con mosaicismo 45,X/46Xdel(X)(q21). Comunicación de un caso
}

\author{
Turner's syndrome $45, X / 46 X \operatorname{del}(X)(q 21)$. A case report
}

\author{
Dra. Delia Aiassa ${ }^{a}$, Lic. Beatriz Bosch ${ }^{a}$ y Méd. Mónica Castellano ${ }^{b}$
}

\begin{abstract}
RESUMEN
El síndrome de Turner fue descrito por Otto Ullrich en 1930 y por Henry Turner en 1938.

Se estima que 1 de 2000 a 3000 niñas recién nacidas, y 1\% de las concepciones de embriones y fetos femeninos portan esta patología, llegándose a abortar espontáneamente, en el primer trimestre, entre el $95 \%$ y el $99 \%$ de los fetos afectados.

El caso que se presenta corresponde a una adolescente, nacida en 1995, que consultó por amenorrea primaria, con cariotipo 45,X[6]/46Xdel(X)(q21)[14]. Dado el resultado observado, se estudió a la madre, quien había experimentado una insuficiencia ovárica prematura y cuyo cariotipo era $46 \operatorname{Xdel}(\mathrm{X})(\mathrm{q} 21)$ [3]/ 46,XX[35].

Palabras clave: sindrome de Turner, mosaicismo, amenorrea primaria.
\end{abstract}

\section{SUMMARY}

Turner's syndrome was described by Otto Ullrich (1930) and Henry Turner (1938). An estimated 1 from 2,000 to 3,000 female babies and $1 \%$ of the conceptions of female embryos and fetuses have this condition, and 95 to $99 \%$ of them result in miscarriage during the first trimester. The case presented concerns a $15 \mathrm{y} / \mathrm{o}$ girl who consulted due to primary amenorrhea. The karyotype was 45,X[6]/46Xdel(X)(q21)[14]. Her mother had experienced premature ovarian failure and her karyotype was: 46Xdel(X)(q21)[3]/46,XX[35].

Keywords: Turner syndrome mosaicism, primary amenorrhea.

http:/ /dx.doi.org/10.5546/aap.2013.e21

\section{INTRODUCCIÓN}

El síndrome de Turner fue descrito por Otto Ullrich en 1930 y por Henry Turner en 1938.

Se estima que 1 de 2500 a 3000 niñas recién nacidas, y $1 \%$ de las concepciones de embriones y fetos femeninos portan esta patología, llegándose a abortar espontáneamente, en el primer trimestre, entre el $95 \%$ y el $99 \%$ de los fetos afectados. ${ }^{1,2}$

a. Laboratorio de Genética, Centro Médico Científico, Departamento de Ciencias Naturales, Universidad Nacional de Río Cuarto.

b. Centro Médico Científico.

Río Cuarto, Córdoba.

Correspondencia:

Dra. Delia Aiassa: daiassa@exa.unrc.edu.ar

Conflicto de intereses: Ninguno que declarar.

Recibido: 21-7-2012

Aceptado: 4-11-2012
Es la alteración más frecuente en los cromosomas sexuales, caracterizada por la ausencia completa o parcial del cromosoma $\mathrm{X} y$, en ocasiones, por mosaicos.

En los mosaicos se observa casi siempre la presencia de dos líneas celulares diferentes con cariotipo distinto. Esta anomalía cromosómica puede explicarse durante la formación del óvulo o los espermatozoides (gametogénesis), o durante el primer período del desarrollo embrionario, en las primeras semanas de gestación. Si el óvulo o el espermatozoide han sufrido esta pérdida cromosómica, el individuo que se forme a partir de la fertilización portará el error cromosómico, mientras que si la pérdida se produce en el período embrionario, podría explicarse la presencia, en un mismo individuo, de células con un contenido genético y cromosómico diferente, teniendo poblaciones celulares con un solo cromosoma $\mathrm{X}$ y poblaciones con dos de ellos. Con la línea celular con cariotipo $45, X$ suelen observarse otras líneas celulares con un número completo de cromosomas, aunque la otra línea celular puede presentar anomalías estructurales del cromosoma $X$ o un cromosoma $Y^{1,3,4}$

\section{PRESENTACIÓN DEL CASO}

Se trata de una adolescente nacida en 1995, segunda hija, con un hermano varón anterior a ella. En octubre de 2010 consulta por amenorrea primaria. No tiene antecedentes de amenorrea en su familia por línea materna ni paterna. La madre presenta un fenotipo normal, sin problemas para lograr los embarazos, con antecedente de insuficiencia ovárica prematura.

En el examen físico se observa un fenotipo femenino normal, leve implantación baja de las orejas y un cuello sin particularidades. Talla 1,56 m y peso $56 \mathrm{~kg}$. Mamas en estadio Tanner 1-2, pubarca y axilarca normales. Sin relaciones sexuales.

Se realiza una ecografía que informa: útero hipotrófico de $4 \mathrm{~cm}$ de longitud. Se visualizan ambos ovarios (sin folículos). Se complementa con un análisis de sangre: rutina normal, FSH 91 $\mathrm{mUI} / \mathrm{ml}$, LH $33 \mathrm{mUI} / \mathrm{ml}$, estradiol menos de 20 $\mathrm{pg} / \mathrm{ml}$. Se repite en el laboratorio de otro centro, 
con los siguientes resultados: FSH $100 \mathrm{mUI} / \mathrm{ml} \mathrm{y}$ estradiol menor a $10 \mathrm{pg} / \mathrm{ml}$.

Se remite a la paciente al laboratorio de genética para la valoración citogenética. Completa los estudios con una ecografía abdominal, cuyo resultado es normal.

\section{Estudio citogenético}

Se realiza un estudio del cariotipo que, en mayo de 2011, informa una fórmula $45, X[6] / 46 X \operatorname{del}(X)(q 21)[14]$, correspondiente a un cariotipo compatible con mosaico de síndrome de Turner (Figura 1).

Dado el resultado, se decide estudiar a la madre, cuyo cariotipo es $46 \operatorname{Xdel}(\mathrm{X})(\mathrm{q} 21)$ [3]/46,XX[35].

\section{Tratamiento}

Se comienza reemplazo hormonal con $17-\mathrm{B}$ estradiol continuo, con buena tolerancia.

El control ecográfico a los 3 meses del tratamiento muestra un útero de $6 \mathrm{~cm}$, buena relación cuerpo/cuello y endometrio lineal. Mamas en estadio Tunner 2-3, peso $62 \mathrm{~kg}$ y talla $1,62 \mathrm{~cm}$.

A los 4 meses de tratamiento, se produce un sangrado. Se agrega progesterona natural micronizada, 7 días por mes, y estradiol diario, y se continúan los controles ambulatorios.

\section{DISCUSIÓN}

En los cariotipos estándares, con resolución de $5 \mathrm{a} 10 \mathrm{Mb}$, se han identificado regiones cromosómicas críticas para la falla ovárica prematura. En un estudio realizado en 99 mujeres, 8 tuvieron va-

FIgURA 1. Metafase donde se observa un cromosoma X $\mathrm{Y}$ otro con la deleción en el brazo largo.

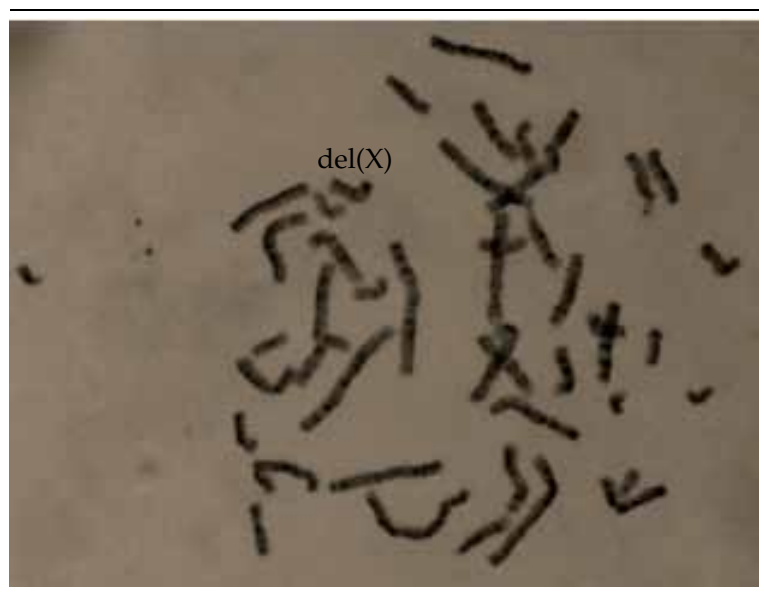

riaciones significativas para el aumento de copias de ADN: 1p21.1, 5p14.3, 5q13.2, 6p25.3, 14q32.33, $16 \mathrm{p} 11.2,17 \mathrm{q} 12$ y Xq28. De estas, cinco genes están involucrados en la reproducción y son genes candidatos potenciales para la falla ovárica prematura. ${ }^{5}$

Las mujeres con duplicación del brazo corto y deleción del brazo largo del cromosoma $X$ se relacionan con falla ovárica, y talla normal o alta. En el caso de las mujeres con falla ovárica prematura es posible la inducción de la ovulación. ${ }^{6}$

La falta del brazo corto del cromosoma X, especialmente de las bandas Xcen a Xp11, causa el clásico síndrome de Turner; mientras que cuando se presenta disgenesia gonadal, están involucradas deleciones en el brazo corto y en el brazo largo del cromosoma $X$, representando un $65 \%$ y un $93 \%$ de los casos, respectivamente. En todos los casos con cromosomas $\mathrm{X}$ isodicéntricos, sea del brazo corto o del brazo largo (idic Xp, idic $\mathrm{Xq}$ ), se informa amenorrea primaria o secundaria. ${ }^{7}$ Se ha sugerido que el fenotipo puede estar estrechamente ligado al patrón de replicación del cromosoma $\mathrm{X}$ y también su comportamiento en la inactivación. ${ }^{8}$ La inactivación del cromosoma $X$ es un fenómeno complejo, ya que no es completa, sino que hay centros de inactivación y centros de expresión de ciertos genes sobre el cromosoma inactivo. Eso explicaría la ausencia o manifestación de síntomas clínicos en una paciente portadora de un cromosoma $\mathrm{X}$ delecionado. ${ }^{9}$

Las pérdidas de segmentos del cromosoma $X$ más amplias se originan en $\mathrm{Xq13}$ y se asocian a amenorrea primaria, falta de desarrollo mamario y falla ovárica completa. Se considera que $\mathrm{Xq13}$ es la región eje para el mantenimiento del ovario y que contiene el centro de inactivación del cromosoma X humano (CIX).

La menstruación ocurre en mujeres con deleciones de puntos de rotura Xq21 o más adelante.

Se estima que las mujeres con delXq21 pueden menstruar, dado que podrían haber retenido una región que contiene un gen de mantenimiento del ovario, lo que no ocurre en aquellas con delXq13, que presentan amenorrea primaria, quienes pueden haber perdido tal locus. En las deleciones Xq más distales no hay amenorrea primaria. ${ }^{10}$ Se han informado casos de pacientes fértiles con deleciones en Xq 25. ${ }^{11}$

Kraus y cols., ${ }^{12}$ describen el caso de una familia en la cual 4 mujeres tuvieron irregularidades menstruales y presentaban una deleción parcial del brazo largo del cromosoma X; 3 de ellas tuvieron falla ovárica entre los 24 y los 37 años. Los 
cariotipos de estas pacientes presentaban un cromosoma $X$ delecionado en el brazo largo. Sin embargo, al realizar el estudio por hibridación del ADN, se observó que la sección delecionada era una parte intersticial del Xq. Estos hallazgos ponen de manifiesto el papel del brazo largo del cromosoma $X$ en la función ovárica y que la agudeza de la citogenética debe ir acompañada, en algunos casos, del análisis molecular del ADN.

También se han comunicado casos de menopausia prematura debido a una deleción heredada en $\mathrm{Xq}$, por lo que la presencia de casos familiares sugiere que debe realizarse una investigación citogenética en las mujeres jóvenes que sufren oligoamenorrea, especialmente cuando sus madres han experimentado menopausia prematura. ${ }^{13}$

Las alteraciones en el cromosoma $X$ pueden ser en número, como cuando se pierde un cromosoma $\mathrm{X}$ y se produce la monosomía, o bien puede haber alteraciones estructurales, mucho más complejas, cuyo estudio requiere mayor experiencia citogenética. Entre estas alteraciones es posible observar deleciones, formación de isocromosomas de brazos cortos o largos del cromosoma X, o cromosoma en anillo.

En relación con las deleciones, es muy importante detectar no sólo la presencia de una alteración estructural, sino también el nivel cromosómico donde ocurrió y definir el área delecionada. Esta precisión permitirá establecer el diagnóstico y el pronóstico, ya que hay algunas pacientes con alteraciones estructurales del cromosoma $X$ que presentan solamente irregularidades menstruales o menopausia prematura, e informes de casos de herencia familiar, en que el asesoramiento genético tiene una importante participación. ${ }^{14}$

Las deleciones en el cromosoma $X$ suelen determinar la presencia de una o muchas características del síndrome de Turner, pero cada una de estas características no puede ser atribuida a una deleción específica.

Las características clínicas varían según la anomalía citogenética que porta la paciente con el síndrome. Los hallazgos clínicos característicos los presentan las pacientes con monosomía $\mathrm{X}$, y de la variedad con isocromosoma del Xq; las pacientes con deleción del Xp tienen estatura baja y mal- formaciones congénitas y aquellas con deleción del Xq a menudo sólo tienen disgenesia gonadal.

La caracterización clínica y citogenética de la paciente, motivo de esta presentación y la de su madre, permiten considerar la relación entre el segmento del cromosoma $X$ involucrado y el funcionamiento ovárico. Queda en evidencia la importancia de la determinación del cariotipo en el estudio de las pacientes con amenorrea primaria, a fin de evaluar los riesgos para su eventual descendencia y brindar un adecuado asesoramiento genético..$^{15}$

\section{BIBLIOGRAFÍA}

1. Morgan T. Turner syndrome. Am Fam Physician 2007;76: 405-10.

2. Nelson LM. Primary ovarian insufficiency. N Engl J Med 2009;360(6):606-14.

3. Sybert V, McCauley E. Turner syndrome. N Engl J Med 2004;351:1227-38.

4. Pantoja M, Mazzi E. Síndrome de Turner. Rev Soc Bol Ped 2006;45:31.

5. Aboura A, Dupas C, Tachdjian G, et al. Array comparative genomic hybridization profiling analysis reveals deoxyribonucleic acid copy number variations associated with premature ovarian failure. J Clin Endocrinol Metab 2009;94(11):4540-6.

6. Madariaga M, Rivera H. Familial inv (X) (p22q22) ovarian dysgenesis in two sisters with the $\mathrm{Xq}$ and fertility in one male carrier. Clin Genet 1997;52:180-3.

7. Therman E, Susman B. The similarity of phenotypic effects caused by $\mathrm{Xp}$ and $\mathrm{Xq}$ deletions in the human female: two hypotesis. Hum Genet 1990;85:175-83.

8. Hu X, Zhu B, Lin H, et al. Study on the relationship between cytogenetics and phenotypic effection Turner s syndrome. J Tongii Med Univ 1996;16:245-8.

9. Teyssier M, Charrin C. Chomosome $\mathrm{X}$ with partial long arm deletion, three cases. J Gynecol Obstet Biol Reprod 1992;21:413-7.

10. Pacheco J. Falla ovárica precoz. An Fac med 2010;71(3): 191-200.

11. Naguib K, Sundareshan T, Babar A, et al. Fertility with deletion Xq25: report of three cases; possible exceptions for critical region hypotesis. Fertil Steril 1988;49:917-9.

12. Krauss C, Turksoy R, Atkins L, et al. Familial premature ovarian failure due to an interstitial deletion of the long arm of the X chromosome. N Engl J Med 1987;317:125-31.

13. Veneman T, Beverstock G, Exalto N, etal. Premature menopause because of an interstitial deletion in the long arm of the X chromosome. Fertil Steril 1991;55:631-3.

14. Cheng S, Gasparini R, Mueller V. Molecular analysis of aberrations of Xp and Yq. Hum Genet 1992;88:379-82.

15. Gardner RJM, Sutherland GR. Chromosomal abnormalities and genetic counseling. 3rd Ed. Oxford: Oxford University Press; 2004. Pág.120. 